\title{
Experimental investigations on built-up cold-formed steel beams connected by resistance spot welding
}

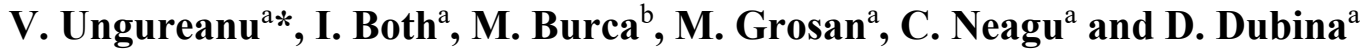 \\ ${ }^{a}$ Department of Steel Structures and Structural Mechanics, Politehnica University of Timisoara, Romania \\ ${ }^{b}$ Department of Materials and Manufacturing Engineering, Politehnica University of Timisoara, Romania \\ *corresponding author, e-mail address: viorel.ungureanu@upt.ro
}

\begin{abstract}
The WELLFORMED research project, ongoing at the CEMSIG Research Center of the Politehnica University of Timisoara, proposes to study a new technological solution for built-up beams made of corrugated steel sheets for the web and thin-walled cold-formed steel profiles for the flanges, connected by resistance spot welding. Within the research project, the experimental work includes tensile-shear tests on the lap joint spot-welded specimens, were different combinations of steel sheets with various thicknesses were tested and, tests on full scale beams in bending. The study intends to demonstrate the feasibility of the proposed solutions, to assess their performance and to enlarge the knowledge by using numerical simulations for the optimization of the current solution and to define the limits of the solution's applicability.
\end{abstract}

Keywords: Built-up beams; cold-formed steel members; corrugated web; resistance spot welding; experimental tests; galvanized steel.

\section{Introduction}

Built-up steel beams, with sinusoidal or trapezoidal corrugated webs, represent a relatively new structural system that has been developed in the last two decades, especially in Germany and Austria. An increased interest for this solution was observed for the mainframe of single storey buildings and steel bridges, respectively. The main advantage of this type of element is the effect of the corrugation in stability problems, leading to increased buckling resistance, with a more economical design. The use of thinner materials leads to lower costs for materials, saving $10-30 \%$ compared to conventional welded beams and over $30 \%$ compared to hot-rolled ones. The height of a common sinusoidal corrugated steel sheet used as web is comparable to a $12 \mathrm{~mm}$ thick flat sheet or more. In the solutions developed so far, the flanges are made of flat sheets, welded to the sinusoidal sheet for the web, involving a specific welding technology. For these elements, the flanges provide the main bending resistance, with a small contribution of the sinusoidal corrugated web that offers shearing capacity. The design of corrugated web beams is included in Annex D of EN 1993-1-5 [1] together with the specific aspects covered by EN 1993-1-1 [2] and EN 1993-1- 3 [3].

A fully cold-formed built-up beam, consisting of trapezoidal corrugated web and parallel flanges made of thin-walled cold-formed steel lipped channel sections, was developed within the CEMSIG Research Center (http://www.ct.upt.ro/en/centre/cemsig) of the Politehnica University of Timisoara [4],[5] in which the connections between the flanges and the web were done by self-drilling screws.

The technical solution presented above [4] was also extended for trapezoidal steel beams [6]. In the latter case, experimental tests were carried out on two beams with a $12 \mathrm{~m}$ span, with different connection arrangements between the flanges and the web.

A detailed state-of-the-art regarding built-up beams using cold-formed steel elements, was presented in [4].

The paper presents the results of the experimental program performed on small specimens, tensile-shear tests on the lap joint spot-welded specimens, and on full scale built- 
up beams of corrugated web beams and coldformed steel profiles as flanges, connected by resistance spot welding.

\section{Experimental tests}

The WELLFORMED research project involves a large experimental program on tensile-shear tests on the lap joint spot-welded specimens, were different combinations of steel sheets with various thicknesses were tested, and tests on full scale beams, to demonstrate the feasibility of the proposed solutions, to assess their performance and to enlarge the knowledge by using numerical simulations for the optimization of the current solution and to define the limits of applicability of the solution by parametric studies.

The proposed new solution is based on an experimental program previously developed within the CEMSIG Research Center, in which five corrugated web beams with flanges of backto-back cold-formed lipped channel steel profiles were tested, having a span of $5157 \mathrm{~mm}$ and a height of $600 \mathrm{~mm}$, with different arrangements/configurations for the self-drilling screws position and for the additional shear panels as shown in [4], [5].

In order to fully investigate the response of full scale built-up beams connected by spot welding, the experimental tests comprised: a) tensile-shear tests on lap joint spot-welded specimens with various thickness combinations, b) tensile tests on base material and c) full scale tests on built-up beams in bending.

\subsection{Tensile-shear tests on lap joint spot-welded specimens}

To understand the behaviour of the built-up beams made of corrugated web beams and coldformed steel profiles as flanges, connected by using spot welding, and for the characterisation of the behaviour of all types of connections, tensile-shear tests on lap joint spot-welded specimens have been performed.

The combinations between different sheet thicknesses, experimentally tested, are shown in Table 1 . The notations $t_{1}$ and $t_{2}$ represent the thicknesses of the steel sheets in the connection and ds is the diameter of the spot welding. The diameter of the spot welding, ds, was determined according to EN 1993-1-3 [3] for the case of resistance welding, i.e. $\mathrm{ds}=5 \sqrt{t}$, where $\mathrm{t}$ is the smallest thickness of the connected steel sheets. A total number of 140 specimens were tested. The dimensions of the specimens, generically represented in Fig. 1, were chosen in accordance with the specifications given in Chapter 8.4 of EN 1993-1-3 [3]. According to EN 1993-1-3 [3], all specimens were connected using one spot of welding. The specimens have been produced using Inverspotter 14000 Smart Aqua equipment from Telwin company, able to control the variables of a spot welding as: welding current, welding time and force between the electrodes in Smart Auto Mode.

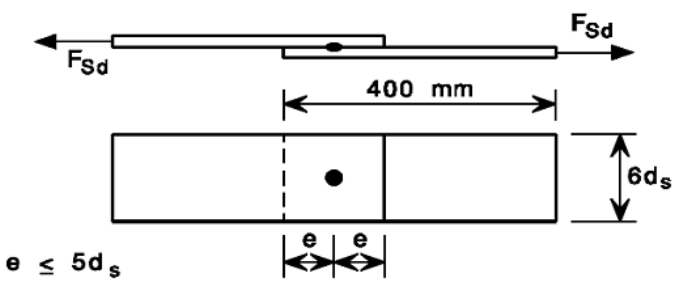

Fig. 1. The dimensions of the specimens according to EN 1993-1-3 [3].

It should be mentioned that a similar experimental program, but focused on 0.7 and $0.8 \mathrm{~mm}$ thicknesses only, was performed by Benzar et al. [7] at the CEMSIG Research Center. The above sheet thickness combinations only concerned the connection of corrugated steel sheets of the web, to ensure the continuity of the web.

Table 1.Types of spot welding specimens (one spot of welding per specimen).

\begin{tabular}{ccccc}
\hline Name & $\begin{array}{c}\boldsymbol{t}_{\mathbf{1}} \\
{[\mathbf{m m}]}\end{array}$ & $\begin{array}{c}\boldsymbol{t}_{\mathbf{2}} \\
{[\mathbf{m m}]}\end{array}$ & $\begin{array}{c}\boldsymbol{d}_{\boldsymbol{s}} \\
{[\mathbf{m m}]}\end{array}$ & $\begin{array}{c}\text { No. of } \\
\text { tests }\end{array}$ \\
\hline SW-0.8-0.8 & 0.80 & 0.80 & 4.5 & 7 \\
SW-0.8-1.0 & 0.80 & 1.00 & 4.5 & 7 \\
SW-0.8-1.2 & 0.80 & 1.20 & 4.5 & 7 \\
SW-0.8-1.5 & 0.80 & 1.50 & 4.5 & 7 \\
SW-0.8-2.0 & 0.80 & 2.00 & 4.5 & 7 \\
SW-0.8-2.5 & 0.80 & 2.50 & 4.5 & 7 \\
SW-1.0-1.0 & 1.00 & 1.00 & 5.0 & 7 \\
SW-1.0-1.2 & 1.00 & 1.20 & 5.0 & 7 \\
SW-1.0-1.5 & 1.00 & 1.50 & 5.0 & 7 \\
SW-1.0-2.0 & 1.00 & 2.00 & 5.0 & 7 \\
SW-1.0-2.0 & 1.00 & 2.50 & 5.0 & 7 \\
SW-1.2-1.2 & 1.20 & 1.20 & 5.5 & 7 \\
SW-1.2-1.5 & 1.20 & 1.50 & 5.5 & 7 \\
SW-1.2-2.0 & 1.20 & 2.00 & 5.5 & 7 \\
SW-1.2-2.5 & 1.20 & 2.50 & 5.5 & 7 \\
SW-1.5-1.5 & 1.50 & 1.50 & 6.1 & 7 \\
SW-1.5-2.0 & 1.50 & 2.00 & 6.1 & 7 \\
SW-1.5-2.5 & 1.50 & 2.50 & 6.1 & 7 \\
SW-2.0-2.0 & 2.00 & 2.00 & 7.1 & 7 \\
SW-2.0-2.5 & 2.00 & 2.50 & 7.1 & 7 \\
\hline
\end{tabular}


Experimental tests were conducted using the UTS universal testing machine. The distance between the sensors of the extensometer was 80 $\mathrm{mm}$. Fig. 2 shows a tested specimen with one spot welding of the SW-1.2-1.5 set, developing the full button pull-out failure.

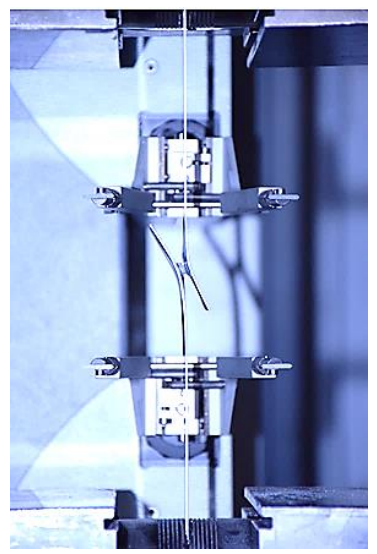

Fig. 2. Full button pull-out failure mode.

Fig. 3 depicts the comparison of the forcedisplacement curves for the specimen set presented above, using different welding regimes. It can be seen that the specimens have a very good capacity and ductility, the maximum recorded force exceeding $12 \mathrm{kN}$.

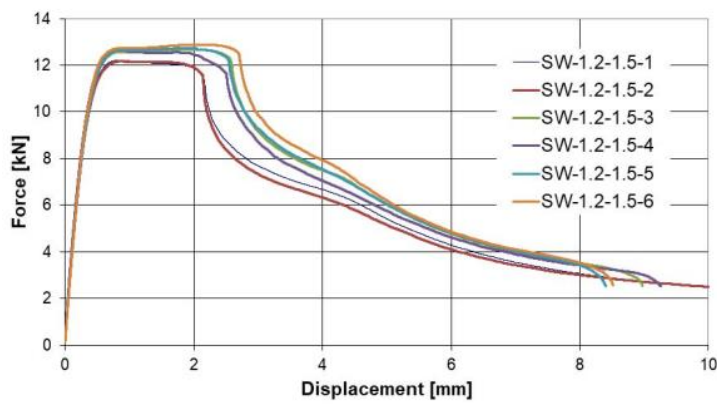

Fig. 3. Force-displacement curves for SW-1.2-1.5 specimens (one spot of welding).

Performing the tests on all the specimens presented in Table 1, the general conclusion that can be drawn is that both the capacity and the ductility of the tested specimens are very good. Moreover, compared to the same specimens tested using self-drilling screws [4],[5], the capacity of the tested specimens is double, but the ductility is decreased.

The tests revealed two types of failure modes, i.e. full button pull-out (nugget pull-out) and interfacial fracture (see Fig. 4). For the investigated combinations of thicknesses, most of them failed by full button pull-out.
In the full button pull-out, the fracture occurs in the base metal or in the perimeter of the weld. In this failure mode, the material is completely torn from one of the sheets with the weld remaining intact. This is the most common failure mode for the tested specimens.

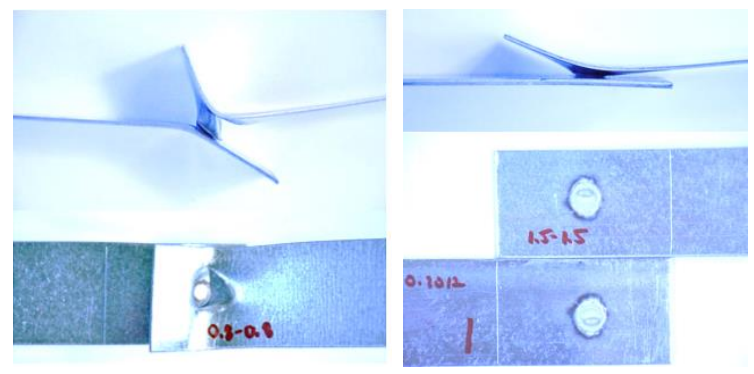

Fig. 4. Failure modes of the spot welding specimens: a) full button pull-out, b) interfacial fracture.

Another type of failure mode is the interfacial fracture in which the weld fails at the interface of the two sheets, leaving half of the weld nugget in one sheet and half in the other.

As a conclusion, in the case of full button pull-out, the strain in the base material outside the weld nugget is greater than the strain developed at the weld interface and the opposite is true for the case of the weld interfacial failure. In addition, from the experimental results, it is noticed that the load-bearing capacity of the weld is not affected by the fracture mode.

The quantitative results, in terms of force displacement curves are presented in 0 .

It may be observed that for each combination the maximum force is not limited by the minimum thickness, as the force increases if a smaller thickness is connected to a thicker sheet, but it exists an upper limit of the bearing capacity of the welded connection which is the equivalent of a plastic force of the smaller thickness.

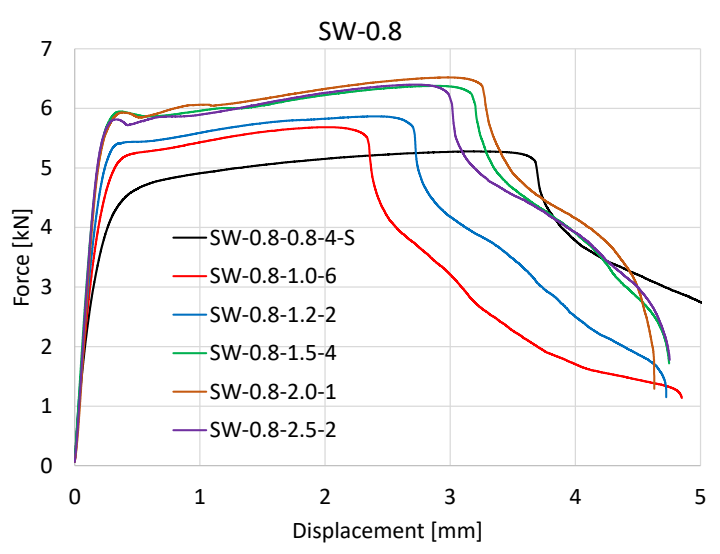

Fig. 5. Response of simple SW specimens. 

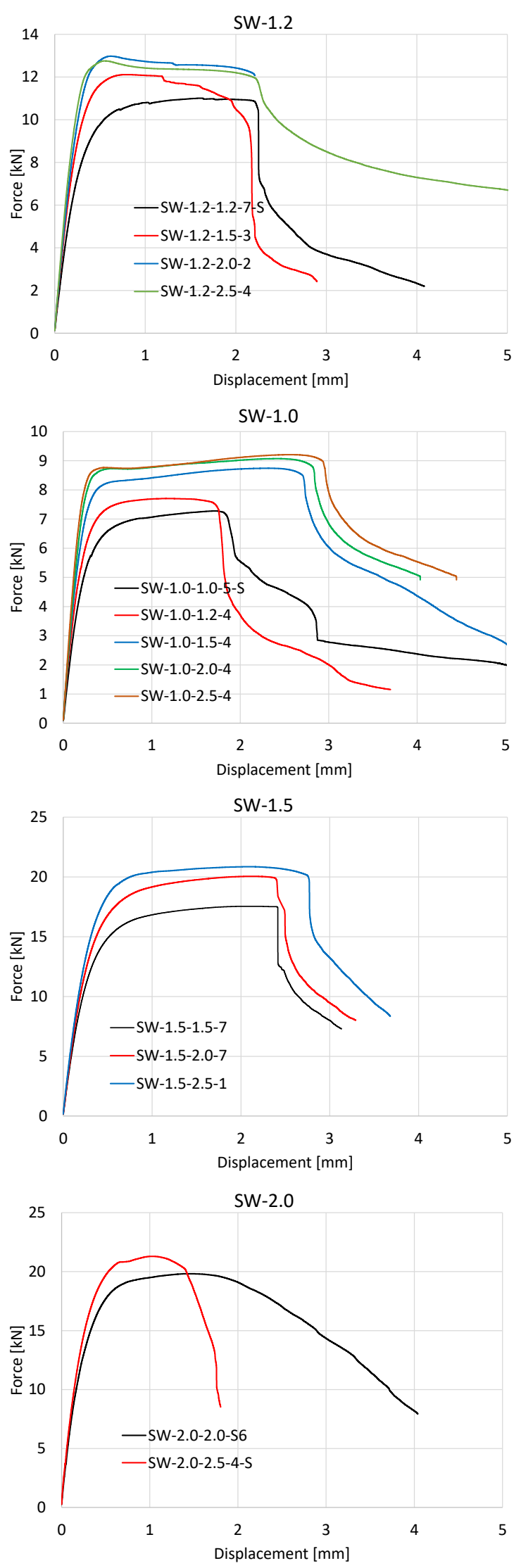

Fig. 5. (continues...).

\subsection{Tensile tests}

Specimens of all the sheet thicknesses that were involved in the built-up beams, i.e. $0.8 \mathrm{~mm}$, $1.0 \mathrm{~mm}, 1.2 \mathrm{~mm}, 1.5 \mathrm{~mm}, 2.0 \mathrm{~mm}$ and $2.5 \mathrm{~mm}$ were prepared for tensile tests with the nominal width of $20 \mathrm{~mm}$. A number of 5 specimens for each thickness was considered.

The mechanical characteristics of the base material were obtained according to the international standard ISO 6892-1 [7]. Experimental tests were conducted using the UTS universal testing machine. The curves presented in Fig. 6 represent a selection from the tests, while the mean values of the tests per each thickness are given in Table 2.

\subsection{Tensile tests}

Specimens of all the sheet thicknesses that were involved in the built-up beams, i.e. $0.8 \mathrm{~mm}$, $1.0 \mathrm{~mm}, 1.2 \mathrm{~mm}, 1.5 \mathrm{~mm}, 2.0 \mathrm{~mm}$ and $2.5 \mathrm{~mm}$ were prepared for tensile tests with the nominal width of $20 \mathrm{~mm}$. A number of 5 specimens for each thickness was considered.

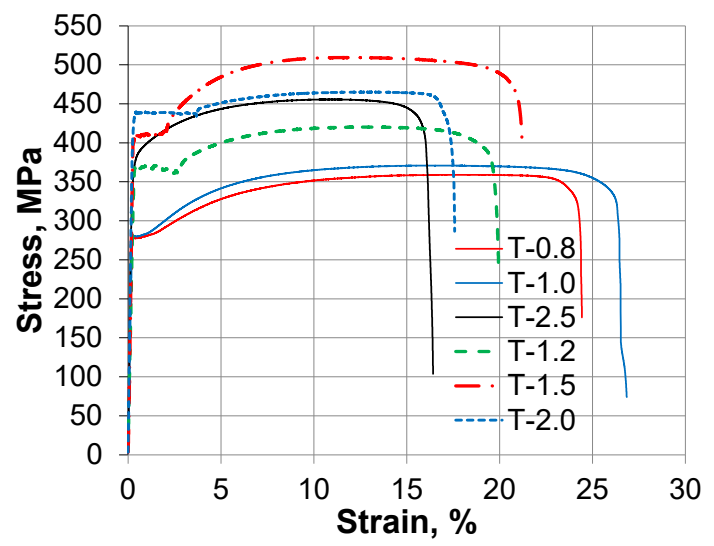

Fig. 6. Stress-strain relationships.

Table 2.Material properties.

\begin{tabular}{cccccc}
\hline $\begin{array}{c}t \\
(\mathrm{~mm})\end{array}$ & $\begin{array}{c}R_{p 0.2} \\
(\mathrm{MPa})\end{array}$ & $\begin{array}{c}R_{e H} \\
(\mathrm{MPa})\end{array}$ & $\begin{array}{c}R_{m} \\
(\mathrm{MPa})\end{array}$ & $\begin{array}{c}A_{g t} \\
\%\end{array}$ & $\begin{array}{c}A_{t} \\
\%\end{array}$ \\
\hline 0.8 & 279.64 & 282.67 & 361.76 & 18.41 & 26.60 \\
1.0 & 281.33 & - & 373.50 & 16.70 & 26.14 \\
1.2 & 366.82 & 367.81 & 420.68 & 13.15 & 19.83 \\
1.5 & 407.70 & 409.00 & 497.12 & 13.06 & 20.38 \\
2.0 & 431.78 & 430.43 & 464.46 & 11.79 & 19.70 \\
2.5 & 374.68 & - & 452.98 & 11.40 & 16.76 \\
\hline where: \\
$R_{p 0.2}$ - stress at $0.2 \%$ strain \\
$R_{e H}$ - maximum value of stress prior to the first \\
decrease in force \\
$R_{m}$ - stress corresponding to the maximum force \\
$A_{g}$ - plastic extension at maximum force \\
$A_{g t}$ - total extension at maximum force \\
$A_{t}$ - total extension at the moment of fracture
\end{tabular}


The mechanical characteristics of the base material were obtained according to the international standard ISO 6892-1 [7]. Experimental tests were conducted using the UTS universal testing machine. The curves presented in Fig. 6 represent a selection from the tests, while the mean values of the tests per each thickness are given in Table 2.

\subsection{Full scale beam specimen tests}

For the full-scale specimen tests, two beams were built-up, i.e. CWB SW-1 and CWB SW-2, having a span of $5157 \mathrm{~mm}$ and a height of 600 $\mathrm{mm}$. The process for the manufacturing consists of 4 steps: a) connecting the corrugated steel sheets for the web, b) connecting the shear panels at the ends of the beam, c) connecting the top and bottom flanges and e) connecting the end parts of the beam for the rigid connection to the experimental stand, as presented in Fig. 7. The first step in only necessary if the corrugated web is not available in one piece. For the current case, the corrugated steel sheets had a maximum length of $1.05 \mathrm{~m}$.

The components of the built-up beams are shown in Fig. 8 and detailed below:

-two back-to-back lipped channel sections for flanges $-2 \times \mathrm{C} 120 / 2.0$; -corrugated steel sheets (panels of $1.05 \mathrm{~m}$ length with $0.8 \mathrm{~mm}$ and $1.2 \mathrm{~mm}$ thicknesses); -additional shear panels - flat plates of 1.0 or $1.2 \mathrm{~mm}$;

-reinforcing profiles U150/2.0 used under the load application points;

-bolts M12 grade 8.8 for flange to endplate connection.

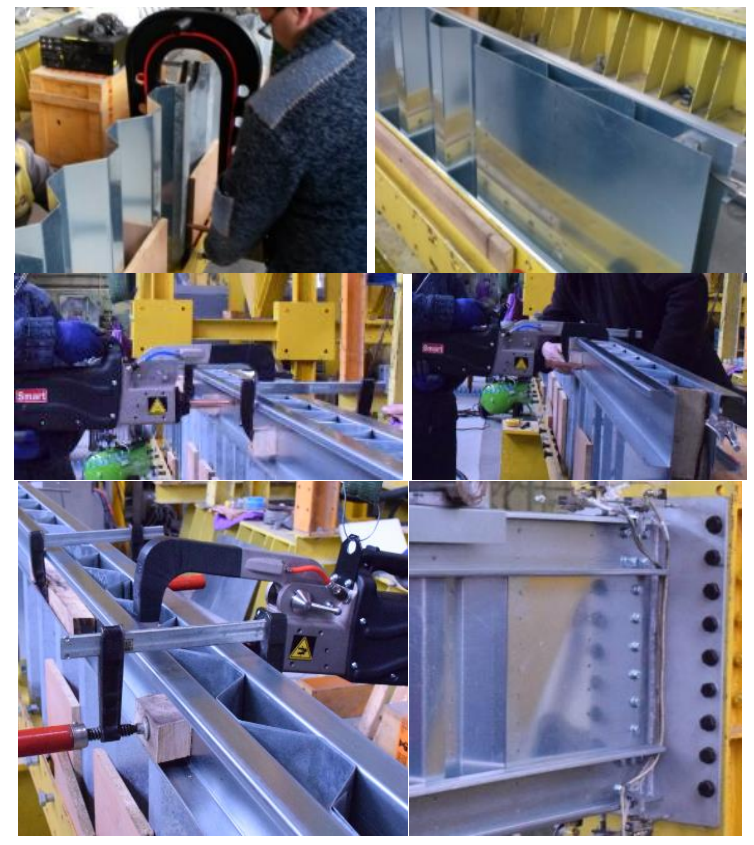

Fig. 7. Stages of beam built-up.

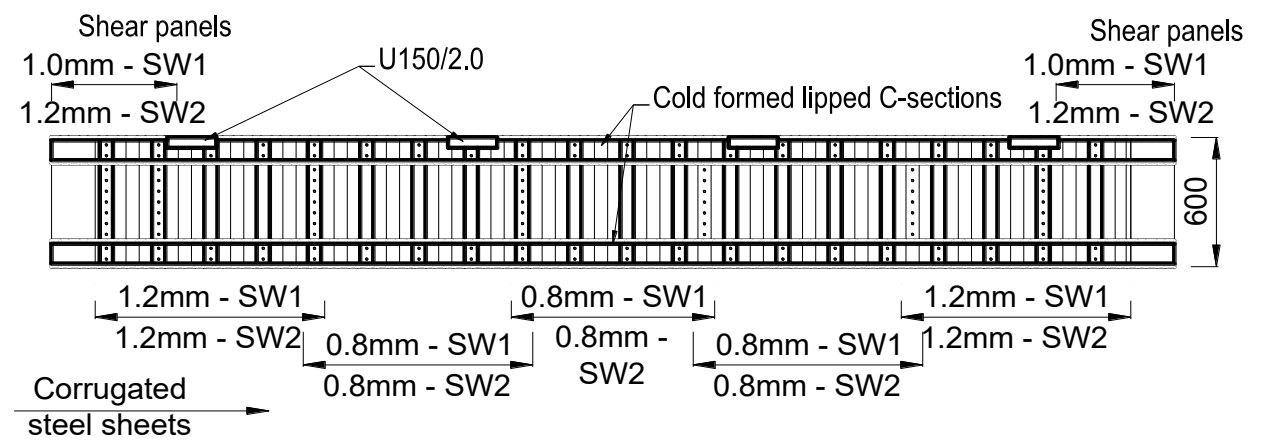

Fig. 8. Components of the built-up beams.
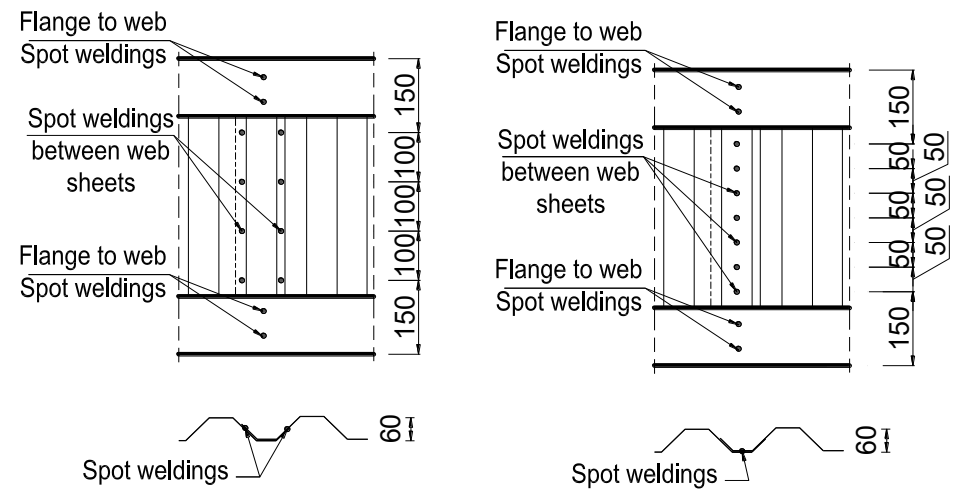

Beam end

Shear panels

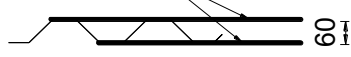

Shear panels positioning

Fig. 9. a) Connection between corrugated sheets of beam CWB SW-1, b) Connection between corrugated sheets of beam CWB SW-2, c) position of the shear panels. 
Except the differences between the shear panel's thicknesses of the two beams, as shown in Fig. 8 and Table 3, another aspect of interest was the connection between the corrugated steel sheets of the web. By using the same number of spot welds, the corrugated sheets of beam CWB SW-1 were connected on two rows (Fig. 9(a)), while the corrugated sheets of beam CWB SW2 were connected on one row only as shown in (Fig. 9(b)).

Table 3.Distribution of the steel sheets used for the web of the spot-welded beams.

\begin{tabular}{|c|c|c|c|c|}
\hline \multirow[b]{2}{*}{ Name } & \multicolumn{3}{|c|}{ Thickness } & \multirow{2}{*}{$\begin{array}{c}\text { Length } \\
\text { of shear } \\
\text { panels }\end{array}$} \\
\hline & $\begin{array}{c}\text { Outter } \\
\text { corrugated } \\
\text { sheets }\end{array}$ & $\begin{array}{c}\text { Inner } \\
\text { corrugated } \\
\text { sheets }\end{array}$ & $\begin{array}{l}\text { Shear } \\
\text { panels }\end{array}$ & \\
\hline $\begin{array}{l}\text { CWB } \\
\text { SW-1 }\end{array}$ & $1.2 \mathrm{~mm}$ & $0.8 \mathrm{~mm}$ & & $\begin{array}{c}470 \mathrm{~mm} ; \\
570 \mathrm{~mm}\end{array}$ \\
\hline $\begin{array}{l}\text { CWB } \\
\text { SW-2 }\end{array}$ & $1.2 \mathrm{~mm}$ & $0.8 \mathrm{~mm}$ & $1.2 \mathrm{~mm}$ & $\begin{array}{l}510 \mathrm{~mm} ; \\
630 \mathrm{~mm}\end{array}$ \\
\hline
\end{tabular}

Finally, the beams were loaded in a 2D loading frame, with the test set-up depicted in Fig. 10. The beams were loaded by an actuator of $500 \mathrm{kN}$ which transmitted the force to the beam by a system able to distribute the load in 4 points. An out-of-plane independent frame was used to avoid stability problems during loading.

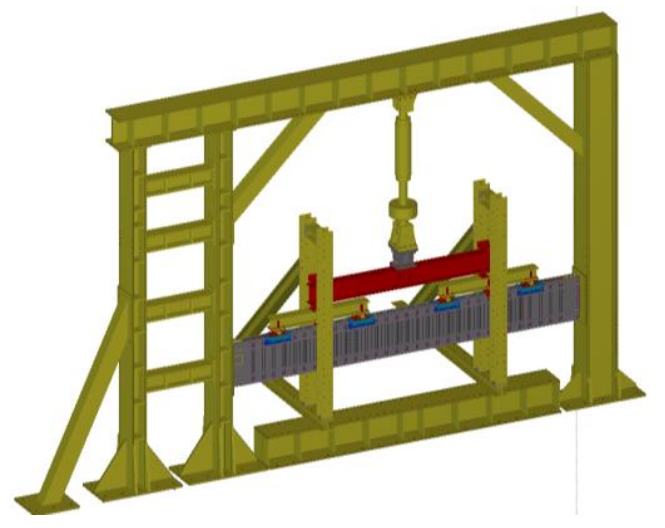

Fig. 10. Test setup.

The recordings aimed to monitor the displacements at each end of the top or bottom flange, between the flange and the end plate as well as between the end plate and the rigid frame, as shown in Fig. 11(a). The vertical deflection of the beam was monitored at each quarter of the span by 2 wire displacement transducers connected to each of the bottom flange part (see Fig. 11(b)). The force was recorded through the actuators load cell.

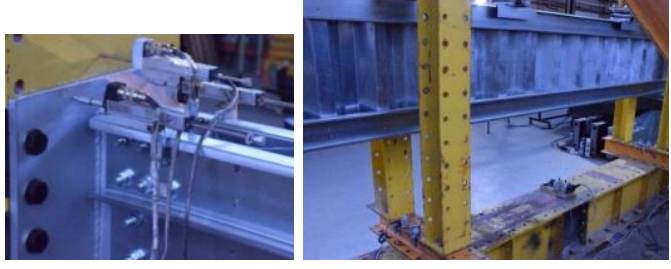

Fig. 11. a) Flange ends instrumentation, b) Vertical deflection instrumentation.

An optical monitoring system was used in order to assess the behaviour of the shear panels during loading. The shear panels were monitored using a digital image correlation system (DIC) provided by ISI-SYS GmbH. Two GT6600 Prosilica series of high resolution cameras (29 Mpix) with $35 \mathrm{~mm}$ lenses, recorded images for a $3 \mathrm{D}$ evaluation of the out of plane displacements and strain of the shear panel, at an acquisition frequency of $1 \mathrm{~Hz}$.

Fig. 12 depicts the evolution during testing of the out of plane deformations $(\mathrm{a} \& \mathrm{~b})$ and the corresponding principal strains $(\mathrm{c} \& \mathrm{~d}$ ) of a given shear panel

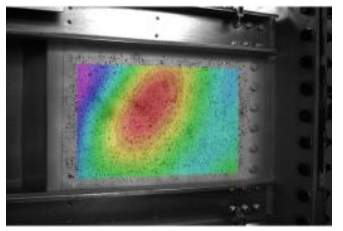

a)

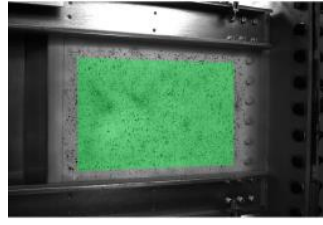

c)

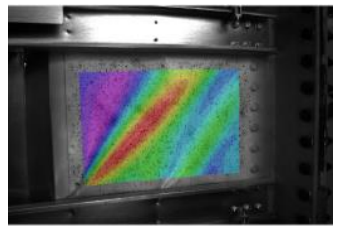

b)

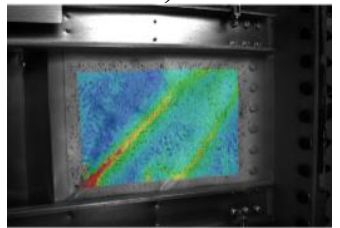

d)
Fig. 12. Evolution of the out of plane deformations $(a, b)$ and the corresponding principal strains $(c, d)$ of a given shear panel.

Although the strains at the beginning of the tests are null, the out-of-plane images recorded imperfections due to fabrication within the range of $-1.4 \mathrm{~mm}$ and $2.0 \mathrm{~mm}$. Also, two lines for the development of the maximum tensile strains are noticed on the shear panel area for that particular case.

\section{Results and discussions}

In the following, the remarks during the experiments are presented and discussed. Since similar failure mechanism was exhibited by both beams, the same remarks are valid for both tests. 
For the first tested specimen, CWB SW-1 (see Fig. 13), the failure mode of the beam started with the buckling of shear panel (see Fig. 14), followed by the distortions of the corrugated web as presented in Fig. 15 and, after reaching the maximum force, the breaking of some spotwelding connections (see Fig. 16). The behaviour of CWB SW-1 beam was ductile, with an initial stiffness of $\mathrm{K}_{0 \text {-Exp }}=11352.6 \mathrm{~N} / \mathrm{mm}$ and the maximum load was reached at $\mathrm{F}_{\max }=283.8$ $\mathrm{kN}$. The collapse appears for a displacement of around $123 \mathrm{~mm}$. The recorded forcedisplacement curve at the mid-span is depicted in Fig. 17.

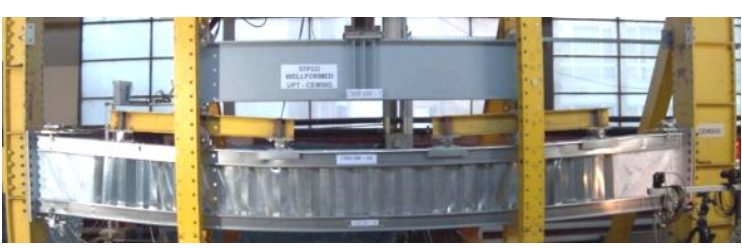

Fig. 13. CWB-SW1 beam - global deformation during the testing.

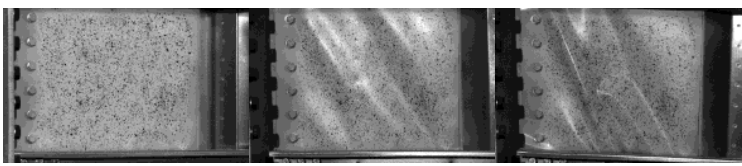

Fig. 14. Development of the shear buckling at the end panels for CWB SW-1 beam.

Fig. 16 presents some details of the web distortion. Due to the two connected points between the web and the flange (see Fig. 11), under the shear stresses, the corrugations have been distorted between the two flanges with respect to the axis between the two spots of the welding.

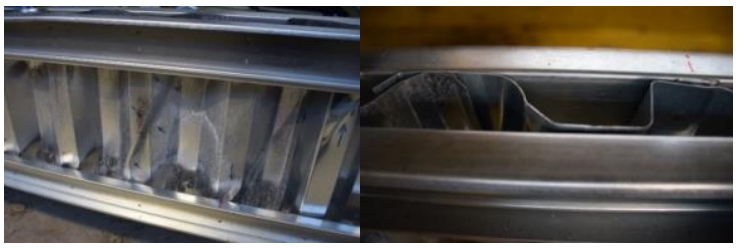

Fig. 15. Distortion of the web corrugation of the CWB SW-1 beam.
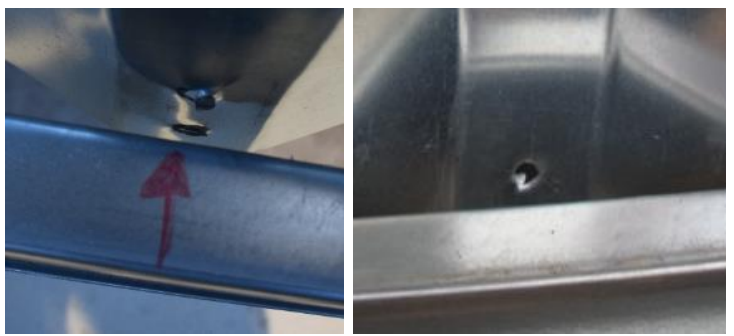

Fig. 16. Development of the shear buckling at the end panels for CWB SW-1 beam.

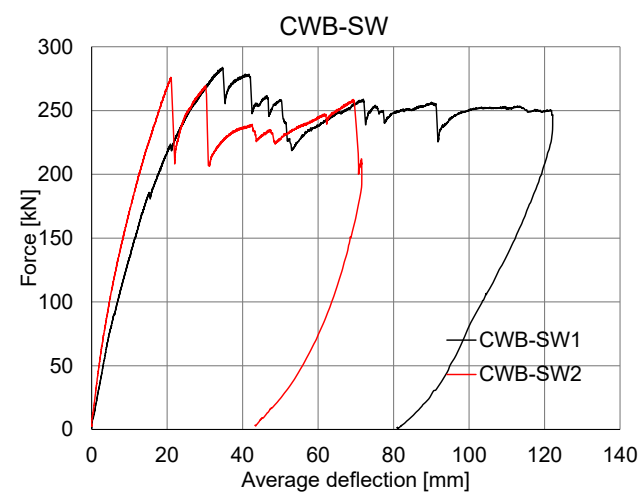

Fig. 17. Force-deflection curve for the full scale built-up beams.

In the final stage of the tests, both beams exhibited local deformation under the load application points, as presented in Fig. 18.

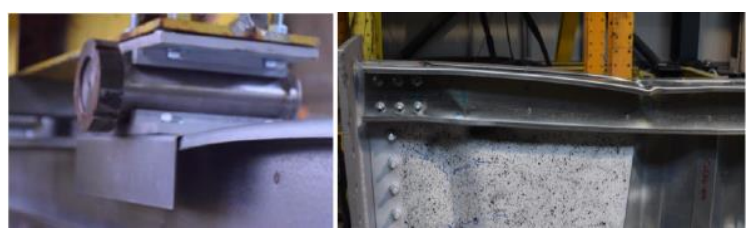

Fig. 18. Local deformations under the load application point.

Compared to the previous studied solution, built-up beams with self-drilling screws [4][5], it may be seen that the beams connected by spot welding present a higher stiffness (see Table 4), as well as a higher capacity (see Fig. 19).

Table 4. Results of the corrugated web beams: spot welding vs. screws.

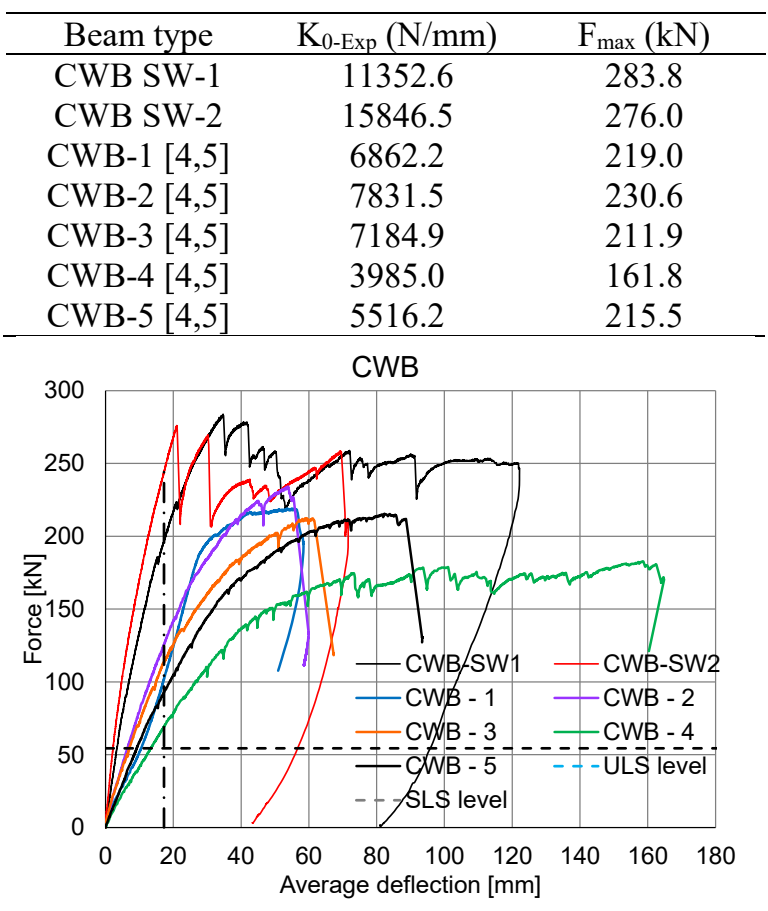

Fig. 19. Force-displacement curve for the full scale beams: spot welding vs. screws. 


\section{Conclusions}

Within the WELLFORMED research project, carried out at the CEMSIG Research Center of the Politehnica University of Timisoara, an extensive experimental program on built-up cold-formed steel beams using resistance spot welding as connecting technology occurred.

The paper presents the experimental results on tensile-shear tests on lap joint spot-welded specimens, in order to characterize the behaviour of these connections and on full scale tests of two beams subjected to bending. The experiments were accompanied by tensile tests, to characterise the material behaviour.

The most common failure mode for the tensile-shear tests on lap joint spot-welded specimens was the full button pull-out. Also, can be noticed that for each combination of thicknesses, the maximum force is not limited by the minimum thickness; the force increases if a smaller thickness is connected to a thicker one, but exists an upper limit which is given by the plastic force of the smaller thickness. Both the capacity and the ductility obtained for the tested specimens are very good and compare to similar specimens tested using self-drilling screws [4][5], the capacity is double but the ductility is decreased.

The experimental results of full scale shown: -both the capacity and the ductility obtained for the tested specimens are very good;

-compared to the solution studied in [4][5], they show an increased capacity but, the deformation is consistent less that the deformation of built-up beams using self-drilling screws.

The results are encouraging and demonstrate the potential of this solution for standardization and industrial manufacturing. Nevertheless, the experimental research will be followed by numerical simulations, to optimize the distribution/arrangement of the spot welding connections, and by parametric studies to see the suitability of such beams to larger spans and the limits of the system

\section{ACKNOWLEDGEMENT}

This work was supported by a grant of the Romanian National Authority for Scientific Research and Innovation, CNCS/CCCDI UEFISCDI, project number PN-III-P2-2.1-PED2016-1684 / WELLFORMED - Fast welding cold-formed steel beams of corrugated sheet web, within PNCDI III.

\section{References}

[1] EN 1993-1-5, Eurocode 3: Design of steel structures - Part 1-5: Plated structural elements, CEN, Brussels, 2006.

[2] EN 1993-1-1, Eurocode 3: Design of steel structures - Part 1-1: General rules and rules for buildings, CEN, Brussels, 2005.

[3] EN 1993-1-3, Eurocode 3: Design of steel structures. Part 1-3: General Rules. Supplementary rules for cold-formed thin gauge members and sheeting, CEN, Brussels, 2006.

[4] Dubina D, Ungureanu V, Gîlia L, Experimental investigations of cold-formed steel beams of corrugated web and built-up section for flanges. Thin-Walled Structures 2015; 90: 159-170.

[5] Dubina D, Ungureanu V, Gîlia L, Cold-formed steel beams with corrugated web and discrete web-to-flange fasteners. Steel Construction 2013; 6(2): 74-81.

[6] Nagy Zs, Ungureanu V, Dubina D, Ballok R, Experimental investigations of cold-formed steel trapezoidal beams of screwed corrugated webs. Proc. of the International Colloquium on Stability and Ductility of Steel Structures SDSS'2016, Timisoara, Romania, 30/05-01/06, 387-394, 2016.

[7] Benzar S, Ungureanu V, Dubina D Burca M. Built-up cold-formed steel beams with corrugated webs connected with spot welding. Advanced Materials Research 2015; 1111: 157162.

[8] EN ISO 6892-1, Metallic materials - tensile testing. Part 1: Method of test at room temperature, CEN, Brussels, 2009. 